\title{
Hepatozoon canis in hunting dogs from Southern Italy: distribution and risk factors
}

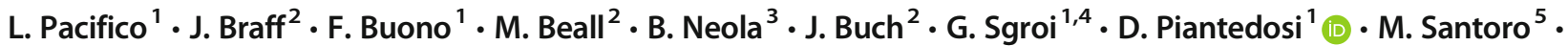 \\ P. Tyrrell ${ }^{2} \cdot$ A. Fioretti ${ }^{1} \cdot$ E. B. Breitschwerdt ${ }^{6} \cdot$ R. Chandrashekar ${ }^{2} \cdot$ V. Veneziano ${ }^{1,7}$
}

Received: 21 March 2020 / Accepted: 16 July 2020 / Published online: 28 July 2020

(C) The Author(s) 2020

\begin{abstract}
Hepatozoon canis is a hemoprotozoan organism that infects domestic and wild carnivores throughout much of Europe. The parasite is mainly transmitted through the ingestion of infected ticks containing mature oocysts. The aims of the present survey were to determine the prevalence of $H$. canis in hunting dogs living in Southern Italy and to assess potential infection risk factors. DNA extracted from whole blood samples, collected from 1433 apparently healthy dogs living in the Napoli, Avellino, and Salerno provinces of Campania region (Southern Italy), was tested by a quantitative real-time polymerase chain reaction (qPCR) assay to amplify $H$. canis. Furthermore, the investigated dog population was also screened by qPCR for the presence of Ehrlichia canis, a major tick-borne pathogen in Southern Italy, in order to assess possible co-infections. Two hundred dogs were $H$. canis PCR-positive, resulting in an overall prevalence of $14.0 \%$ (CI 12.2-15.9). Breed category $(P<0.0001)$, hair coat length $(P=$ $0.015)$, and province of residence $(P<0.0001)$ represented significant risk factors for $H$. canis infection. The presence of $H$. canis DNA was also significantly associated with $E$. canis PCR positivity $(P<0.0001)$. Hunting dogs in Campania region (Southern Italy) are frequently exposed to $H$. canis, and the infection is potentially associated with close contact with wildlife. Further studies are needed to assess the pathogenic potential of $\mathrm{H}$. canis, as well as the epidemiological relationships between hunting dogs and wild animal populations sharing the same habitats in Southern Italy.
\end{abstract}

Keywords Hepatozoon canis $\cdot$ Hunting dogs $\cdot$ Vector-borne diseases $\cdot$ Italy $\cdot$ PCR

Section Editor: Domenico Otranto

D. Piantedosi

dapiante@unina.it

1 Department of Veterinary Medicine and Animal Productions, Università degli Studi di Napoli "Federico II", Naples, Italy

2 IDEXX Laboratories, Inc., Westbrook, ME 04092, USA

3 Istituto Zooprofilattico Sperimentale del Mezzogiorno, Portici, Italy

4 Department of Veterinary Medicine, University of Bari Aldo Moro, Valenzano, Italy

5 Stazione Zoologica Anton Dohrn, Naples, Italy

6 Comparative Medicine Institute, College of Veterinary Medicine, North Carolina State University, Raleigh, NC 27607, USA

7 Osservatorio Faunistico Venatorio - Regione Campania, Naples, Italy

\section{Introduction}

Canine hepatozoonosis is a vector-borne disease (VBD) caused by hemoprotozoan organisms of the genus Hepatozoon (phylum Apicomplexa: Adeleorina), transmitted by ticks (Ixodidae). Currently, two Hepatozoon species are known to infect dogs and other wild canids: Hepatozoon canis (James 1905) and Hepatozoon americanum (Vincent-Johnson et al. 1997). H. canis is widely distributed in several countries of Europe, Asia, Africa, and America, while H. americanum has been reported only from the North American continent (Giannelli et al. 2013; Léveillé et al. 2019). The main vector of $H$. canis is considered to be the brown dog tick, Rhipicephalus sanguineus sensu lato (Baneth et al. 2007), and recently, an experimental study has also confirmed the vectorial role of Rhipicephalus turanicus (Giannelli et al. 2017); other tick species such as Amblyomma ovale, Haemaphysalis longicornis, Haemaphysalis flava, and Rhipicephalus (Boophilus) microplus could be potential vectors of this protozoan parasite (Baneth 2011; de Miranda et al. 
2011; Otranto et al. 2011; Orkun and Nalbantoğlu 2018; Léveillé et al. 2019). Transmission to vertebrate hosts occurs through the ingestion of the infected tick vectors, which harbor mature oocysts of H. canis (Baneth 2011); after merogonic phase in dog tissues, micromerozoites invade the neutrophils and monocytes, where they mature into gamonts that represent the infective stage for the tick (Baneth et al. 2007). Other routes of infection are the transplacental transmission from the dam to the puppies (Murata et al. 1993). In contrast to $H$. americanum, the transmission by ingestion of $H$. canis monozoic cysts from paratenic host during predation has not been demonstrated (Baneth and Shkap 2003; Baneth 2011).

Based upon H. canis epidemiological studies in dogs performed across Europe, the infection prevalence is often correlated to seasonality and the suspected tick vector distribution (Baneth 2011; Otranto et al. 2011; Dantas Torres et al., 2012). Indeed, autochthonous cases were commonly reported where $R$. sanguineus s.l. was endemic (Baneth 2011; Aktas et al. 2015; Ebani et al. 2015; Attipa et al. 2017). However, in recent years, the occurrence of $H$. canis in dogs has been described in areas where $R$. sanguineus s.l. was not found (Hornok et al. 2013; Mitková et al. 2016) and often in association with the presence of $H$. canis in foxes and other wild carnivores (Miterpáková et al. 2017; Hodžić et al. 2018).

Canine hepatozoonosis has generally been characterized as a subclinical infection in dogs. In some cases, infection has been reported in association with clinical signs, such as fever, lethargy, weight loss, and lymphadenomegaly. However, these clinical signs often overlap with those of other diseases (Baneth 2011; Otranto et al. 2011; Giannelli et al. 2013). Furthermore, immunosuppressive chemotherapy or concurrent infections can cause $H$. canis reactivation (Baneth et al. 2003). Immunosuppressed, immunodeficient, and co-infected dogs, in particular, are more likely to develop clinical signs in association with $H$. canis infections (Baneth 2012). Although generally considered an organism of low pathogenicity, rare reports of acute hepatozoonosis, associated with $H$. canis, have been characterized by severe anemia, splenitis, skeletal muscle involvement, and meningoencephalomyelitis (Marchetti et al. 2009).

In Italy, canine hepatozoonosis, associated with H. canis, has only been reported in a few clinical case studies or in association with descriptions of diagnostic testing methods (Gavazza et al. 2003; Sasanelli et al. 2009, 2010; Otranto et al. 2011). Large epidemiological surveys involving defined dog populations are sporadic (Cassini et al. 2009; Ebani et al. 2015). As $R$. sanguineus s.l. is the most widespread tick species on the Italian peninsula (Maurelli et al. 2018), hunting dogs may have an increased risk for acquiring $H$. canis due to increased frequency of tick exposure and closer contact with wildlife compared with pet dogs (Piantedosi et al. 2017; Veneziano et al. 2018; Santoro et al. 2019). The aims of this study were to determine the $H$. canis prevalence in hunting dogs living in Southern Italy and to assess the potential risk factors associated with infection. Furthermore, DNA amplification of Ehrlichia canis, that is, the most common tick-borne pathogen (TBP) agent in Southern Italy, was obtained in order to verify the possible association with $H$. canis infection, considering that both pathogens can be transmitted by the same tick vector species.

\section{Material and methods}

\section{Study area}

The study was conducted in conjunction with the hunting dog's health assistance program of University of Naples and was supported by the management committees of the respective hunting districts (ATCs). The region of study encompassed a surface area of $5698.81 \mathrm{~km}^{2}$, including the hunting district of Napoli (ATC NA), Avellino (ATC AV), and one of the two hunting districts of Salerno (ATC SA 1). These are located in Southern Italy in the provinces of Napoli $\left(40^{\circ} 50^{\prime} \mathrm{N}-14^{\circ} 15^{\prime} \mathrm{E}\right)$, Avellino ( $40^{\circ} 54^{\prime} 55^{\prime \prime} \mathrm{N}-14^{\circ} 47^{\prime} 22^{\prime \prime}$ E), and Salerno ( $\left.40^{\circ} 41^{\prime} 00^{\prime \prime} \mathrm{N}-14^{\circ} 47^{\prime} 00^{\prime \prime} \mathrm{E}\right)$. The territory of the three provinces is contiguous, with Napoli and Salerno overlooking the Tyrrhenian Sea. The coastal area has a typical Mediterranean temperate climate that becomes progressively continental in the adjacent inland and mountainous areas.

\section{Study animals and sample size}

A total of 1433 apparently healthy hunting dogs from 153 municipalities representative of the three provinces were included in the study. Between March and November 2015, blood samples were collected by cephalic vein venipuncture from each dog during routine health checks, performed in 44 private veterinary clinics located in the study area. The blood collection did not provide for any segregation or stress of the animal. Each sample was placed in tubes containing potassium ethylene diamine tetra-acetic acid (EDTA), stored at $80^{\circ} \mathrm{C}$ and, defrosted immediately before batch analysis. The study was approved by the Ethical Animal Care and Use Committee of the University of Naples "Federico II" (number of approval 0039904, October 2014). Written informed consent was obtained from the owners of the hunting dogs included in the study.

The necessary sample size to estimate prevalence was calculated using the formula proposed by Thrustfield (1995) considering the following epidemiological data: expected prevalence of $8 \%$ for $H$. canis based on the results of a similar study in canine populations from Southern Europe (René-Martellet et al. 2015); confidence interval (99\%) and desired absolute precision (2\%), based on the number of hunters in Campania 
region ( $\mathrm{n}^{\circ} 38,611$ hunters in the season $2014-2015$ and assuming a dog for each hunter) (BURC 2014).

A questionnaire was submitted to each owner to obtain information about the dog's residence locality (province), breed category (hound, pointing, mixed-breed), type of coat (short, medium, and long hair), age, gender, pack size when cohabiting with other dogs, contact with other pet or farm animals (dogs, cats, horses, and ruminants), living environment (rural or urban), number of hunting months, type of hunted species (wild mammals or birds), history of tick infestation, and ectoparasite control practices (frequency of ectoparasiticide treatment).

\section{Molecular assay}

H. canis and E. canis real-time PCR was performed at a commercial laboratory (IDEXX Reference Laboratories, West Sacramento, CA, USA). The target sequences for the $H$. canis and E. canis tests were the small subunit ribosomal $(s s r)$ and thio-disulfide oxidoreductase $(d s b)$ genes, respectively. Briefly, $90 \mu \mathrm{l}$ of whole blood was resuspended in guanidinium thiocyanate-based lysis solution and incubated for $10 \mathrm{~min}$. Total nucleic acid was isolated on a MagMax96Flex (ThermoFisher) with magnetic beads (Roche Diagnostics) using the manufacturer's guidelines. Total nucleic acid was eluted in $150 \mu \mathrm{l}$ of PCR-grade nuclease-free water (ThermoFisher) and $5 \mu l$ amplified in subsequent single-plex real-time PCR reactions. Analysis was performed on a Roche Light Cycler 480 (Roche Diagnostics) and raw data analyzed using the 2 nd derivative maximum method with the" high sensitivity" setting to generate crossing points (CP values). Real-time PCR was performed in conjunction with six quality controls, including quantitative PCRpositive control, PCR-negative control, negative extraction control, quantitative DNA internal sample quality control targeting the host $18 \mathrm{~S}$ rRNA gene complex, an internal positive control spiked into the lysis solution, and an environmental contamination monitoring control. All assays were designed and validated according to industry standards (Applied Biosystems 2019).

A subset of $21 \mathrm{H}$. canis and $19 \mathrm{E}$. canis PCR-positive samples were selected for bidirectional Sanger sequencing (University of Delaware DNA Sequencing and Genotyping Center). Amplicons for sequencing were obtained through conventional PCR. The PCR assays consisted of $1 \times$ PCR Buffer (Roche Diagnostics), $2.5 \mathrm{mM} \mathrm{MgCl}_{2}$ (Roche Diagnostics), $200 \mu \mathrm{M}$ mixed nucleotides, $2 \mathrm{U}$ ActiTaq exo DNA polymerase (Roche Diagnostics), and $0.5 \mu \mathrm{M}$ of each primer (TIB MOLBIOL). The cycling profile consisted of 45 cycles of denaturation at $95{ }^{\circ} \mathrm{C}$, annealing at $60^{\circ} \mathrm{C}$, and extension at $72{ }^{\circ} \mathrm{C}$. A 745-bp region of the H. canis ssr gene was amplified with primers Hc-sfp (5' CCG TGG CAG TGA CGG TTA A $3^{\prime}$ ) and Hc-rfp (5' GAA GGA GTC GTT TAT
AAA GAC GAC CT 3'). For E. canis, a 372-bp region of the $d s b$ gene was amplified with primers Ec-sfp (5' GCA AAA TGA TGT CTG AAG ATA TGA AAC A $\left.3^{\prime}\right)$ and Ec-srp (5' CAC CAC CGA TAA ATG TAT CCC CTA 3'). Sequence homology was determined through BLAST®N analysis (BLASTN 2.9.0+).

\section{Statistical analysis}

To test the effects of risk factors on the probability of testing positive for $H$. canis DNA, a multiple logistic regression was performed. The PCR status (positive vs negative) was considered a response variable, while the risk factors collected on the questionnaire were considered as predictor variables. Proportion positive for $H$. canis DNA was evaluated for each predictor variable, and Clopper-Pearson exact binomial limits were used to determine $95 \%$ confidence intervals. Multiple logistic regression was performed using a subset of the predictor variables to determine the odds ratios (OR). Of the 1433 dogs enrolled in the study, 1416 had complete data for the predictor variables and were included in the model. All statistical analyses were performed using SAS software (Version 9.4, SAS Institute Inc., Cary NC) and considering $P<0.05$ as the threshold for statistical significance. Firth bias-correction was implemented in the multiple logistic regression to address quasi-complete separation due to zero H. canis DNA positive dogs from Napoli province.

\section{Results}

Two hundred of the 1433 dogs were $H$. canis PCR-positive, with an overall prevalence of $14.0 \%$ (200/1433; 95\% CI $12.2-$ 15.9\%). Thirty-six dogs were PCR-positive to E. canis (36/ 1433; 95\% CI 27.9-61.9\%) and 16 animals were co-infected by both $H$. canis and $E$. canis. The distribution of the $H$. canis PCR-positive dogs in the study area is shown in Fig. 1. Sequencing of PCR identified $H$. canis as the only species of Hepatozoon spp. circulating in dog populations investigated. The sequences showed $99 \%$ homology with the corresponding sequence from other dog isolate GenBank sequence MK091085 (H. canis isolate 9992-3). The analysis of E. canis sequences showed $99-100 \%$ homology with GenBank sequences MK783026 (E. canis isolate R46) and CP000107 (E. canis strain Jake).

The proportions of $H$. canis PCR-positive dogs in relation to the potential risk factors associated with exposure to the parasite are summarized in Table 1. The multiple logistic regression model was developed using risk factors that were expected to be important based upon the biology of the infection or relevant epidemiology. Using a robust model, the presence of $H$. canis DNA was significantly associated with a dog's breed category $(P<0.0001)$, hair coat length $(P=$ 


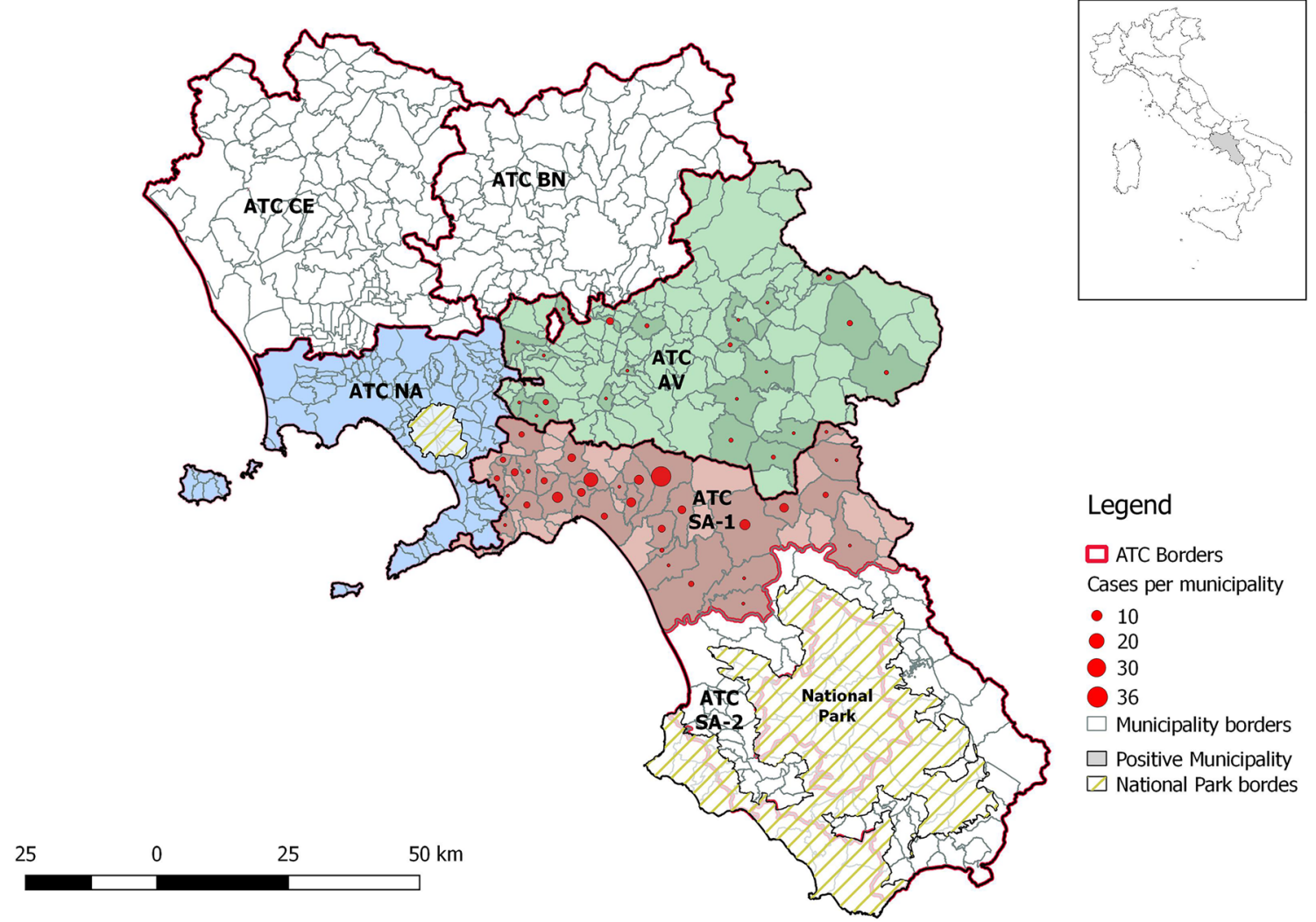

Fig. 1 Distribution map of Hepatozoon canis PCR-positive hunting dogs in the study area by hunting districts

$0.015)$, and living province $(P<0.0001)$; furthermore, a positive correlation was found between $H$. canis and $E$. canis infection $(P<0.0001)$ (Table 1$)$. Risk was higher in dogs with medium (OR 1.89; 95\% CI 1.01-3.55) and long hair coat (OR 1.74; 95\% CI 1.15-2.62), and in hound breed dogs (OR 1.29; 95\% CI 0.64-2.62). Dogs living in Salerno province had the highest risk (OR 5.46; 95\% CI 3.56-8.38), while dogs from Napoli area had the lowest risk (OR 0.03; 95\% CI 0.00-0.56) for $H$. canis positivity (Table 2). Gender, age, pack size, frequency of ectoparasitic treatment, and tick infestation history were not significantly correlated with $H$. canis infection.

\section{Discussion}

Our results indicate that hunting dogs in Southern Italy are frequently infected with $H$. canis. Comparative data for the general dog population of Campania region are not available; however, studies performed in other areas confirm the presence of $H$. canis throughout Italy. In Central-Northern Italy, Cassini et al. (2009) reported a $H$. canis PCR prevalence of $3.63 \%$ in kennel and hunting dogs (14/385) in a molecular survey involving vector-borne pathogens (VBPs). Ebani et al. (2015) reported a $H$. canis prevalence of $32.5 \%$ (38/ 117 ) in hunting dogs from Central Italy. In addition to other possibilities, these discrepancies with respect to our results may be explained by the different sampling periods (DantasTorres et al. 2012) and the spread of $R$. sanguineus s.l. in the different areas of the Italian peninsula (Maurelli et al. 2018). In fact, $R$. sanguineus $\mathrm{s} .1$ is considered the most prevalent tick species in Southern Italy as there are favorable climatic conditions for its development and survival (Otranto et al. 2014). In a study performed on ticks collected from owned dog populations, the overall prevalence of $R$. sanguineus s.l. in Southern Italy was $36.1 \%$ (Maurelli et al. 2018).

The presence and the prevalence of $H$. canis in its major competent vector, $R$. sanguineus s.l., were also investigated in the southern regions of Italian peninsula. In the Apulia region, Ramos et al. (2014) have reported on 1091 off-host ticks, collected from the environment monthly for 1 year, a $H$. canis prevalence of $13.47 \%$. However, in the same area, Dantas-Torres et al. (2012) have showed a lower H. canis prevalence of $2.2 \%$ in ticks collected from dogs living in a kennel where an outbreak of canine hepatozoonosis was registered. Both studies found that the presence of the pathogen agent in ticks occurred mostly in warmer seasons, suggesting that the infection in dogs could be more noticeable in summer or in autumn (after the peak of tick abundance) and highlighting the importance of vector seasonality in the dynamic of the infection (Dantas-Torres 2010). Despite widespread distribution of $R$. sanguineus s.l. in Campania region, $H$. canis PCR prevalence reported in hunting dogs in this study was found to 
Table 1 PCR prevalence (\%) and confidence interval (95\%) of H. canis in hunting dogs in Southern Italy

\begin{tabular}{|c|c|c|c|c|}
\hline Variable & Level & Sample* & Prevalence $(\%)$ H. canis PCR-positive & $95 \% \mathrm{CI}$ \\
\hline \multirow[t]{3}{*}{ Province } & Avellino & 552 & 6.5 & $4.6-8.9$ \\
\hline & Salerno & 641 & 25.6 & $22.2-29.1$ \\
\hline & Napoli & 240 & 0.0 & $0.0-0.0$ \\
\hline \multirow[t]{3}{*}{ Coat } & Long & 791 & 12.6 & $10.4-15.2$ \\
\hline & Medium & 80 & 22.5 & $13.9-33.2$ \\
\hline & Short & 558 & 14.7 & $11.9-17.9$ \\
\hline \multirow[t]{4}{*}{ Breed } & Hound & 525 & 20.2 & $16.8-23.9$ \\
\hline & Mixed-breed & 59 & 22.0 & $12.3-34.7$ \\
\hline & Other & 22 & 22.7 & $7.8-45.4$ \\
\hline & Pointing & 821 & 9.1 & $7.3-11.3$ \\
\hline \multirow[t]{2}{*}{ Tick infestation history } & No & 714 & 12.0 & $9.7-14.7$ \\
\hline & Yes & 712 & 16.0 & $13.4-18.9$ \\
\hline \multirow[t]{2}{*}{ Gender } & Female & 642 & 12.2 & $9.7-14.9$ \\
\hline & Male & 789 & 15.5 & $13-18.2$ \\
\hline \multirow[t]{2}{*}{ Living environment } & Rural Area & 1356 & 14.5 & $12.7-16.5$ \\
\hline & Urban Area & 71 & 4.2 & $0.9-11.9$ \\
\hline \multirow[t]{2}{*}{ Cohabitation with other pet or farm animals } & No & 143 & 13.3 & $8.2-20$ \\
\hline & Yes & 1284 & 14.1 & $12.2-16.1$ \\
\hline \multirow[t]{2}{*}{ Bird hunting } & No & 611 & 21.4 & $18.2-24.9$ \\
\hline & Yes & 816 & 8.5 & $6.6-10.6$ \\
\hline \multirow[t]{2}{*}{ Wild mammal hunting } & No & 813 & 8.4 & $6.6-10.5$ \\
\hline & Yes & 614 & 21.5 & $18.3-25$ \\
\hline \multirow[t]{2}{*}{ Ehrlichia canis PCR result } & Negative & 1397 & 13.2 & $11.4-15.1$ \\
\hline & Positive & 36 & 44.4 & $27.9-61.9$ \\
\hline
\end{tabular}

*Totals by category vary due to missing data

be lower than in previous reports. A high $H$. canis infection rate $(50.6 \% ; 42 / 83)$ was reported in dogs from a kennel heavily infested with $R$. sanguineus s.l. in the Apulia region (Otranto et al. 2011). Although these findings are from

Table 2 Logistic regression results for the risk factor effect associated with Hepatozoon canis positivity for hunting dogs in Southern Italy

\begin{tabular}{|c|c|c|c|c|c|}
\hline Factor & Level & Reference category & Odds ratio $(95 \% \mathrm{CI})$ & Degrees of freedom & $P$ value \\
\hline Age & & & $1.02(0.95-1.09)$ & 1 & 0.5601 \\
\hline Pack size & & & $0.97(0.94-1.01)$ & 1 & 0.1244 \\
\hline Ectoparasiticide treatments/year & & & $1.02(0.98-1.06)$ & 1 & 0.3733 \\
\hline \multirow[t]{3}{*}{ Province } & & & & 2 & $<0.0001$ \\
\hline & Napoli & Avellino & $0.03(0.00-0.56)$ & & \\
\hline & Salerno & Avellino & $5.46(3.56-8.38)$ & & \\
\hline \multirow[t]{3}{*}{ Coat } & & & & 2 & 0.015 \\
\hline & Long & Short & $1.74(1.15-2.62)$ & & \\
\hline & Medium & Short & $1.89(1.01-3.55)$ & & \\
\hline \multirow[t]{4}{*}{ Breed } & & & & 3 & $<0.0001$ \\
\hline & Hound & Mixed-breed & $1.29(0.64-2.62)$ & & \\
\hline & Pointing & Mixed-breed & $0.38(0.18-0.79)$ & & \\
\hline & Other & Mixed-breed & $0.88(0.26-3.00)$ & & \\
\hline Gender & Male & Female & $1.37(0.98-1.92)$ & 1 & 0.0637 \\
\hline
\end{tabular}


Southern Italy, they differ from the current study, perhaps due to characteristics of the population in that the current study involved a larger sample size and owned dogs that regularly received ectoparaciticide treatments.

Based upon previous TBP agent studies involving hunting dogs living in the same area of Italy, H. canis appears to be the organism with the highest PCR prevalence, and potentially the lowest virulence. For example, Pantchev et al. (2017) in the same area reported a PCR prevalence of $2.4 \%$ for Anaplasma platys and $1.9 \%$ for E. canis. Veneziano et al. (2018) reported Babesia canis and Babesia vogeli PCR prevalences of $0.15 \%$ and $1.1 \%$, respectively. The higher prevalence of $H$. canis compared with the other $R$. sanguineus s.l--associated TBP is supported by studies performed in other endemic areas. Ebani et al. (2015) found an H. canis PCR infection rate of $32.5 \%$ versus $1.7 \%$ for $E$. canis. In Turkey, Aktas and Ozubek (2017) reported H. canis as the most prevalent hemoprotozoan pathogen (54.3\%) followed by Babesia spp. (4.6\%). In a recent survey performed in Iraq, $H$. canis was the most prevalent VBP in dogs (33\%) and wild carnivores (jackals $49.1 \%$ and foxes $47.3 \%$ ) (Otranto et al. 2019). Potentially, the discrepancy between $H$. canis compared with other VBP prevalences may be related to different transmission routes. Dogs could ingest an infected tick from their haircoats while grooming, before the ectoparasite has the chance to take a blood meal and transmit other pathogens. Furthermore, the ingestion of ticks during hunting activities could increase the possibility of developing infection even in the presence of ectoparasite treatments applied to the dog.

An interesting epidemiological aspect is the demonstration of $H$. canis within temperate lineages of $R$. sanguineus s.l., widespread in Mediterranean areas (Demoner et al. 2013; Dantas-Torres and Otranto 2015). It is known that not all lineages of $R$. sanguineus s.l. are competent to host $E$. canis, and the presence of this major VBP correlates to the tropical lineage of $R$. sanguineus (Moraes-Filho et al. 2015). In a study performed in a kennel from the Apulia region with a higher number of dogs positive for $H$. canis, $R$. sanguineus sp. I (temperate lineage) was reported as the competent vector for this pathogen (Otranto et al. 2011; Dantas-Torres and Otranto 2015). Furthermore, Latrofa et al. (2014) showed the presence of $H$. canis in $R$. sanguineus sp. I and sp. III belonged to temperate lineages, while none of ticks belonged to tropical lineage were found positive. In our study, the higher prevalence of $H$. canis compared with other VBPs, as E. canis, could be also explained by a different availability of susceptible vectors. However, studies to assess the $R$. sanguineus s.l. lineages in the study area would be necessary to confirm this hypothesis.

In this hunting dog population, breed category was a significant risk factor for acquiring $H$. canis infection. Hounds, particularly when compared with pointing breeds used for hunting birdlife, could have greater $H$. canis-infected tick exposure due to their strict contact with hunted wild mammals. In fact, as reported by other authors (Ebani et al. 2015; Piantedosi et al. 2017), the close contact with wild mammals or bush/woodland, required by this type of hunting, seemingly results in more frequent exposures for hunting dogs to several TBDs. Fighting and/or biting during hunting places the dog at increased risk of ingesting a parasitized tick on the prey or being exposed to ticks that subsequently infest the dogs (Baneth et al., 2011). It is noteworthy that the acquisition of $H$. americanum infection was described also through carnivorism (Baneth 2011), but this potential transmission route is still not demonstrated for $H$. canis, although Baneth and Shkap (2003) reported the presence of $H$. canis monozoic cysts in the spleen of experimentally and naturally infected dogs.

According to previous surveys, there was not an association with gender (Rojas et al. 2014; Lauzi et al. 2016; Aktas et al., 2017; Licari et al. 2017), although male dogs had a slightly increased, but not significant, risk of contracting H. canis infection in the present study. Due to their predilection for roaming behavior, male dogs may have higher environmental exposure to TBDs. In agreement with most previous studies, the rate of $H$. canis infection was not significantly associated with age in our hunting dog population (Rojas et al. 2014; Lauzi et al. 2016). In contrast, Aktas et al. (2015) described a higher infection prevalence in adult dogs, possibly related to a longer duration of vector exposure.

Our data indicates a significantly higher prevalence in medium and long hair dogs, because the hard ticks can cling and attach more easily and not be noticed, as previously described (Hornok et al. 2006). Finally, differences in $H$. canis prevalence between the studied areas highlight that geographical effects, including vector density, activity patterns, and other factors, influence a dog's exposure to tick-borne pathogens. It is important to point out that in the province of Salerno there are large tracks of wooded areas that contain high wildlife densities (Pittiglio et al. 2018). Furthermore, the Salerno province has the highest concentration of boar hunter teams, with an average number of dogs per packs equal to 4.8 dogs (with a maximum of 25 dogs). It is s noteworthy that previous studies from some European countries (Hungary, Czech Republic, Slovakia, and Austria) involving wild fauna have demonstrated a high $H$. canis prevalence in foxes even in the absence of R. sanguineus s.1. (Tolnai et al. 2015; Mitková et al. 2016; Mirtepáková et al., 2017; Hodžić et al. 2018). This phenomenon could be explained by the vertical transmission of parasite from female foxes to the offspring (Hodžić et al. 2018). In these countries where the $R$. sanguineus is lacking, it is still unclear whether sharing the territory with foxes could represent a real risk factor for dogs. In our study, living in the more urbanized province of Napoli, where most of the animals are used for bird hunting, has 
proved to be a protective factor for hunting dogs $(0 \%$ of 240 dogs; Table 2). Furthermore, the bird hunters of Napoli province had smaller dog packs (only 1 or 2 dogs for each hunter), and the animals received a better routine care, such as a more frequent ectoparasitic treatments. The average number of ectoparasitic treatment months was 9.0, 7.2, and 4.7 for Napoli, Salerno, and Avellino provinces, respectively (Veneziano et al. 2013).

In our study, there was a correlation between PCR amplification of $H$. canis and E. canis DNA. Co-infection of $H$. canis with other VBPs is not uncommon (Mundim et al. 2008), and canine ehrlichiosis, associated with E. canis, represents the most common TBD in the study area (Piantedosi et al. 2017). H. canis gamonts and E. canis morulae have been visualized in the same monocyte in a stained blood smear from a dog (Baneth et al. 2015). The presence of $H$. canis might enhance cellular invasion by other VBPs or could potentiate the pathogenicity of other organisms, such as Leishmania infantum, E. canis, and Mycoplasma haemocanis (Baneth et al. 2015; Attipa et al. 2017, 2018). Nevertheless, a clinical association between $H$. canis infection and the worsening of symptoms for pathogenic VBDs (leishmaniosis and ehrlichiosis) has not been confirmed (Mylonakis et al. 2005; Attipa et al. 2018; Baxarias et al. 2018).

\section{Conclusions}

In conclusion, hunting dogs in Southern Italy are exposed to $H$. canis infection. The prevalence of $H$. canis infection is substantially greater than other regional TBPs. Further studies are necessary to better understand the epidemiological and clinical aspects of this protozoan infection among hunting dogs. Moreover, it would be interesting to clarify the parasite transmission modalities related to the relationship between hunting dogs and sympatric wildlife populations.

Acknowledgments The authors thank Dr. Paolo Varuzza for data processing and map creation.

Authors' contributions Experimental conception and design: Diego Piantedosi and Vincenzo Veneziano. Collection of samples: Laura Pacifico, Giovanni Sgroi, Benedetto Neola, Francesco Buono, and Mario Santoro. Molecular analysis: Melissa Beall, Jesse Buch, Ramaswamy Chandrashekar, and Phyllis Tyrrell. Statistical analysis: Jennifer Braff and Melissa Beall. Analysis and interpretation: Vincenzo Veneziano, Diego Piantedosi, Ramaswamy Chandrashekar, Melissa Beall, Jesse Buch, Alessandro Fioretti, Laura Pacifico, and Edward B. Breitschwerdt. Paper writing: Laura Pacifico, Diego Piantedosi, Melissa Beall, Edward B. Breitschwerdt, and Vincenzo Veneziano. All authors read and approved the final manuscript.

Funding information Open access funding provided by Università degli Studi di Napoli Federico II within the CRUI-CARE Agreement. The study was supported by the management committees of the hunting districts of Napoli (ATC NA), Avellino (ATC AV), and Salerno (ATC SA 1).

Data availability The data supporting the conclusions of this article are included within the article.

\section{Compliance with ethical standards}

Conflict of interest The authors declare that they have no conflict of interest.

Ethics approval and consent to participate The study was approved by the Ethical Animal Care and Use Committee of the University of Naples "Federico II" (number of approval 0039904; date of approval 20 October 2014), and written informed consent was obtained from the owners of the dogs included in the study.

Open Access This article is licensed under a Creative Commons Attribution 4.0 International License, which permits use, sharing, adaptation, distribution and reproduction in any medium or format, as long as you give appropriate credit to the original author(s) and the source, provide a link to the Creative Commons licence, and indicate if changes were made. The images or other third party material in this article are included in the article's Creative Commons licence, unless indicated otherwise in a credit line to the material. If material is not included in the article's Creative Commons licence and your intended use is not permitted by statutory regulation or exceeds the permitted use, you will need to obtain permission directly from the copyright holder. To view a copy of this licence, visit http://creativecommons.org/licenses/by/4.0/.

\section{References}

Aktas M, Ozubek S (2017) A survey of canine haemoprotozoan parasites from Turkey, including molecular evidence of an unnamed Babesia. Comp Immunol Microbiol Infect Dis 52:36-42

Aktas M, Özübek S, Altay K, Balkaya İ, Utuk AE, Kırbas A, Şimsek S, Dumanl NA (2015) A molecular and parasitological survey of Hepatozoon canis in domestic dogs in Turkey. Vet Parasitol 209(Suppl 3-4):264-267

Applied Biosystems (2019) User Bulletin \#3. http://tools.thermofisher. com/content/sfs/manuals/cms_041001.pdf. Accessed 20 Aug 2019

Attipa C, Hicks CAE, Barker EN, Christodoulou V, Neofytou K, Mylonakis ME, Siarkou VI, Vingopoulou EI, Soutter F, Chochlakis D, Psaroulaki A, Papasouliotis K, Tasker S (2017) Canine tick-borne pathogens in Cyprus and a unique canine case of multiple co-infections. Ticks Tick Borne Dis 8:341-346

Attipa C, Solano-Gallego L, Papasouliotis K, Soutter F, Morris D, Helps C, Carver S, Tasker S (2018) Association between canine leishmaniosis and Ehrlichia canis co-infection: a prospective casecontrol study. Parasit Vectors 11:184. https://doi.org/10.1186/ s13071-018-2717-8

Baneth G (2011) Perspectives on canine and feline hepatozoonosis. Vet Parasitol 181(Suppl 1):3-11

Baneth G (2012) Hepatozoon canis infection. In: Greene CE (ed) Infectious diseases of the dog and cat, 4th edn. Elsevier, Oxford, pp 750-757

Baneth G, Shkap V (2003) Monozoic cysts of Hepatozoon canis. J Parasitol 89(Suppl 2):379-381

Baneth G, Mathew JS, Shkap V, Macintire DK, Barta JR, Ewing SA (2003) Canine hepatozoonosis: two disease syndromes caused by separate Hepatozoon spp. Trends Parasitol 19(Suppl 1):27-31 
Baneth G, Samish M, Shkap V (2007) Life cycle of Hepatozoon canis (Apicomplexa: Adeleorina: Hepatozoidae) in the tick Rhipicephalus sanguineus and domestic dog (Canis familiaris). J Parasitol 93(Suppl 2):283-299

Baneth G, Harrus S, Gal A, Aroch I (2015) Canine vector-borne coinfections: Ehrlichia canis and Hepatozoon canis in the same host monocytes. Vet Parasitol 208(Suppl 1-2):30-34

Baxarias M, Álvarez-Fernández A, Montserrat-Sangrà S, Ordeix L, Rojas A, Nachum-Biala Y, Baneth G, Solano-Gallego L (2018) Does coinfection with vector-borne pathogens play a role in clinical canine leishmaniosis? Parasit Vectors 11(Suppl 1):135. https://doi.org/10. 1186/s13071-018-2724-9

BURC (2014) Bollettino Ufficiale Regione Campania n. 35, 20 Giugno 2014 Calendario per l'annata venatoria 2014-2015. http://burc. regione.campania.it

Cassini R, Zanutto S, Frangipane di Regalbono A, Gabrielli S, Calderini P, Moretti A, Tampieri MP, Pietrobelli M (2009) Canine piroplasmosis in Italy: epidemiological aspects in vertebrate and invertebrate hosts. Vet Parasitol 165(Suppl 1-2):30-35

Dantas-Torres F (2010) Biology and ecology of the brown dog tick, Rhipicephalus sanguineus. Parasit Vectors 3:26. https://doi.org/10. 1186/1756-3305-3-26

Dantas-Torres F, Otranto D (2015) Further thoughts on the taxonomy and vector role of Rhipicephalus sanguineus group ticks. Vet Parasitol 208(1-2):9-13. https://doi.org/10.1016/j.vetpar.2014.12.014

Dantas-Torres F, Latrofa MS, Weigl S, Tarallo VD, Lia RP, Otranto D (2012) Hepatozoon canis infection in ticks during spring and summer in Italy. Parasitol Res 110(Suppl 2):695-698

de Miranda RL, de Castro JR, Olegário MM, Beletti ME, Mundim AV, O'Dwyer LH, Eyal O, Talmi-Frank D, Cury MC, Baneth G (2011) Oocysts of Hepatozoon canis in Rhipicephalus (Boophilus) microplus collected from a naturally infected dog. Vet Parasitol 177(3-4):392-396

Demoner L, Rubini AS, Paduan K, Metzger B, de Paula AJM, Martins TF, Mathias MI, O’Dwyer LH (2013) Investigation of tick vectors of Hepatozoon canis in Brazil. Ticks and tick-borne diseases 4(6): 542-546. https://doi.org/10.1016/j.ttbdis.2013.07.006

Ebani VV, Nardoni S, Fognani G, Mugnaini L, Bertelloni F, Rocchigiani G, Papini RA, Stefani F, Mancianti F (2015) Molecular detection of vector-borne bacteria and protozoa in healthy hunting dogs from Central Italy. Asian Pac J Trop Biomed 5(Suppl 2):108-112

Gavazza A, Bizzeti M, Papini R (2003) Observations on dogs found naturally infected with Hepatozoon canis in Italy. Rev Med Vet 154:565-571

Giannelli A, Ramos RA, Dantas-Torres F, Mencke N, Baneth G, Otranto D (2013) Experimental evidence against transmission of Hepatozoon canis by Ixodes ricinus. Ticks Tick Borne Dis 4(Suppl 5):391-394

Giannelli A, Lia RP, Annoscia G, Buonavoglia C, Lorusso E, DantasTorres F, Baneth G, Otranto D (2017) Rhipicephalus turanicus, a new vector of Hepatozoon canis. Parasitology 144(Suppl 6):730 737

Hodžić A, Mrowietz N, Cézanne R, Bruckschwaiger P, Punz S, Habler VE, Tomsik V, Lazar J, Duscher GG, Glawischnig W, Fuehrer HP (2018) Occurrence and diversity of arthropod-transmitted pathogens in red foxes (Vulpes vulpes) in western Austria and possible vertical (transplacental) transmission of Hepatozoon canis. Parasitology 145(Suppl 3):335-344

Hornok S, Edelhofer R, Farkas R (2006) Seroprevalence of canine babesiosis in Hungary suggesting breed predisposition. Parasitol Res 99(Suppl 6):638-642

Hornok S, Tánczos B, Fernández de Mera IG, de la Fuente J, HofmannLehmann R, Farkas R (2013) High prevalence of Hepatozoon-infection among shepherd dogs in a region considered to be free of Rhipicephalus sanguineus. Vet Parasitol 196(Suppl 1-2):189-193

James SP (1905) A new Leucocytozoon of dogs. BMJ 1:1364
Latrofa MS, Dantas-Torres F, Giannelli A, Otranto D (2014) Molecular detection of tick-borne pathogens in Rhipicephalus sanguineus group ticks. Ticks Tick Borne Dis 5(6):943-946. https://doi.org/ 10.1016/j.ttbdis.2014.07.014

Lauzi S, Maia JP, Epis S, Marcos R, Pereira C, Luzzago C, Santos M, Puente-Payo P, Giordano A, Pajoro M, Sironi G, Faustino A (2016) Molecular detection of Anaplasma platys, Ehrlichia canis, Hepatozoon canis and Rickettsia monacensis in dogs from Maio Island of Cape Verde archipelago. Ticks Tick Borne Dis 7(Suppl 5):964-969

Léveillé AN, Baneth G, Barta JR (2019) Next generation sequencing from Hepatozoon canis (Apicomplexa: Coccidia: Adeleorina): complete apicoplast genome and multiple mitochondrion-associated sequences. Int J Parasitol 49:375-387

Licari E, Takács N, Solymosi N, Farkas R (2017) First detection of tick pathogens of dogs from Malta. Ticks Tick Borne Dis 8(Suppl 3): 396-399

Marchetti V, Lubas G, Baneth G, Modenato M, Mancianti F (2009) Hepatozoonosis in a dog with skeletal involvement and meningoencephalomyelitis. Vet Clin Pathol 8(Suppl 1):121-125

Maurelli MP, Pepe P, Colombo L, Armstrong R, Battisti E, Morgoglione ME, Counturis D, Rinaldi L, Cringoli G, Ferroglio E, Zanet S (2018) A national survey of Ixodidae ticks on privately owned dogs in Italy. Parasit Vector 11(Suppl 1):420. https://doi.org/10.1186/s13071018-2994-2

Miterpáková M, Komjáti-Nagyová M, Hurníková Z, Víchová B (2017) Retrospective molecular study on canine hepatozoonosis in Slovakia - does infection risk for dogs really exist? Ticks Tick Borne Dis 8(Suppl 4):567-573

Mitková B, Hrazdilová K, Steinbauer V, D’Amico G, Mihalca AD, Modrý D (2016) Autochthonous Hepatozoon infection in hunting dogs and foxes from the Czech Republic. Parasitol Res 115(Suppl 11):4167-4171

Moraes-Filho J, Krawczak FS, Costa FB, Soares JF, Labruna MB (2015) Comparative evaluation of the vector competence of four South American populations of the Rhipicephalus sanguineus group for the bacterium Ehrlichia canis, the agent of canine monocytic ehrlichiosis. PLoS One 10(9):e0139386. https://doi.org/10.1371/ journal.pone. 0139386

Mundim AV, Morais IA, Tavares M, Cury MC, Mundim MJ (2008) Clinical and hematological signs associated with dogs naturally infected by Hepatozoon sp. and with other hematozoa: a retrospective study in Uberlândia, Minas Gerais, Brazil. Vet Parasitol 153(Suppl $1-2): 3-8$

Murata T, Inoue M, Tateyama S, Taura Y, Nakama S (1993) Vertical transmission of Hepatozoon canis in dogs. J Vet Med Sci 55(Suppl 5):867-868

Mylonakis ME, Leontides L, Gonen L, Billinis C, Koutinas AF, Baneth G (2005) Anti-Hepatozoon canis serum antibodies and gamonts in naturally-occurring canine monocytic ehrlichiosis. Vet Parasitol 129:229-233

Orkun O, Nalbantoğlu S (2018) Hepatozoon canis in Turkish red foxes and their ticks. Vet Parasitol Reg Stud Reports 13:35-37

Otranto D, Dantas-Torres F, Weigl S, Latrofa MS, Stanneck D, de Caprariis D, Capelli G, Baneth G (2011) Diagnosis of Hepatozoon canis in young dogs by cytology and PCR. Parasit Vectors 4:55. https://doi.org/10.1186/1756-3305-4-55

Otranto D, Dantas-Torres F, Giannelli A, Latrofa MS, Cascio A, Cazzin S, Ravagnan S, Montarsi F, Zanzani SA, Manfredi MT, Capelli G (2014) Ticks infesting humans in Italy and associated pathogens. Parasit Vectors 7:328. https://doi.org/10.1186/1756-3305-7-328

Otranto D, Iatta R, Baneth G, Cavalera MA, Bianco A, Parisic A, DantasTorres F, Colella V, McMillan-Colef AC, Chomelg B (2019) High prevalence of vector-borne pathogens in domestic and wild carnivores in Iraq. Acta Trop 197:105058. https://doi.org/10.1016/j. actatropica.2019.105058 Epub 2019 Jun 8 
Pantchev N, Veneziano V, Piantedosi D, Neola B, D’Alessio N, Di Prisco F, Santoro M, Pacifico L, Sgroi G, Auletta L, Leutenegger C, Tyrrell P, Buch J, Ramaswamy C (2017) Serologic and molecular diagnostic survey of vector-borne disease-causing pathogens in hunting dogs from Southern Italy. In: $26^{\text {th }}$ WAAVP International Conference. Kuala Lumpur 406

Piantedosi D, Neola B, D'Alessio N, Di Prisco F, Santoro M, Pacifico L, Sgroi G, Auletta L, Buch J, Breitschwerdt EB, Veneziano V (2017) Seroprevalence and risk factors associated with Ehrlichia canis, Anaplasma spp., Borrelia burgdorferi sensu lato, and D. immitis in hunting dogs from southern Italy. Parasitol Res 116(Suppl 10): 2651-2660

Pittiglio C, Khomenko S, Beltran-Alcrudo D (2018) Wild boar mapping using population-density statistics: from polygons to high resolution raster maps. PLoS One 13(5):e0193295. https://doi.org/10.1371/ journal.pone. 0193295

Ramos RA, Giannelli A, Carbone D, Baneth G, Dantas-Torres F, Otranto D (2014) Occurrence of Hepatozoon canis and Cercopithifilaria bainae in an off-host population of Rhipicephalus sanguineus sensu lato ticks. Ticks Tick Borne Dis 5(3):311-314. https://doi.org/10. 1016/j.ttbdis.2013.12.005

René-Martellet M, Lebert I, Chêne J, Massot R, Leon M, Leal A, Badavelli S, Chalvet-Monfray K, Ducrot C, Abrial D, Chabanne L, Halos L (2015) Diagnosis and incidence risk of clinical canine monocytic ehrlichiosis under field conditions in Southern Europe. Parasit Vectors 8:3. https://doi.org/10.1186/s13071-014-0613-4

Rojas A, Rojas D, Montenegro V, Gutiérrez R, Yasur-Landau D, Baneth G (2014) Vector-borne pathogens in dogs from Costa Rica: first molecular description of Babesia vogeli and Hepatozoon canis infections with a high prevalence of monocytic ehrlichiosis and the manifestations of co-infection. Vet Parasitol 199(Suppl 3-4):121128

Santoro M, Auriemma C, Lucibelli MG, Borriello G, D’Alessio N, Sgroi G, Veneziano V, Galiero G, Fusco G (2019) Molecular detection of Babesia spp. (Apicomplexa: Piroplasma) in free-ranging canids and mustelids from southern Italy. Front. Vet. Sci. 6:269. https://doi.org/ $10.3389 /$ fvets.2019.00269

Sasanelli M, Paradies P, Lubas G, Otranto D, de Caprariis D (2009) Atypical clinical presentation of coinfection with Ehrlichia, Babesia and Hepatozoon species in a dog. Vet Rec 164:22-23

Sasanelli M, Paradies P, Greco B, Eyal O, Zaza V, Baneth G (2010) Failure of imidocarb dipropionate to eliminate Hepatozoon canis in naturally infected dogs based on parasitological and molecular evaluation methods. Vet Parasitol 171(Suppl 3-4):194-199

Thrustfield M (1995) Veterinary epidemiology. Blackwell Science Ltd London, pp 138-188

Tolnai Z, Sréter-Lancz Z, Sréter T (2015) Spatial distribution of Anaplasma phagocytophilum and Hepatozoon canis in red foxes (Vulpes vulpes) in Hungary. Ticks Tick Borne Dis. 6(5):645-648. https://doi.org/10.1016/j.ttbdis.2015.05.009

Veneziano V, Auletta L, Neola B, Pasolini MP, Barra G, Raffaele A, Cortese L, Di Loria A, Piantedosi D (2013) A questionnaire survey on ectoparasite control practices on hunting dogs in Salerno and Avellino provinces of Campania region (South Italy). VIII International Symposium on Wild Fauna León, Spain, October $31^{\text {th }}$-November $3^{\text {th }}$ O.303: 81

Veneziano V, Piantedosi D, Ferrari N, Neola B, Santoro M, Pacifico L, Sgroi G, D'Alessio N, Panico T, Leutenegger CM, Tyrrell P, Buch J, Breitschwerdt EB, Chandrashekar R (2018) Distribution and risk factors associated with Babesia spp. infection in hunting dogs from Southern Italy. Ticks Tick Borne Dis 9(Suppl 6):1459-1463

Vincent-Johnson NA, MacIntire DK, Lindsay DS, Lenz SD, Baneth G, Shkap V, Blagburn BL (1997) A new Hepatozoon species from dogs: description of the causative agent of canine hepatozoonosis in North America. J Parasitol 83:1165-1172

Publisher's note Springer Nature remains neutral with regard to jurisdictional claims in published maps and institutional affiliations. 